\title{
Redesigning First Year Anatomy and Physiology Subjects for Allied Health Students: Introducing Active Learning Experiences for Physiology in a First Semester Subject
}

\author{
Pam L. Megaw and Monika A. Zimanyi ${ }^{\mathrm{b}}$ \\ Corresponding author: Pam L. Megaw, pam.megaw@jcu.edu.au \\ aBiomedicine, College of Public Health, Medical and Veterinary Science, James Cook University, Townsville \\ QLD 4810, Australia \\ ${ }^{\mathrm{b}}$ Anatomy, College of Medicine and Dentistry, James Cook University, Townsville QLD 4810, Australia
}

Keywords: flipped classroom, student engagement, academic performance

\begin{abstract}
In this paper we describe the initial development of flipped classroom learning activities for the physiology component of a first year anatomy and physiology class for allied health students, and the subsequent transformation to focus on active learning strategies over a period of three years. The learning activities incorporated included the use of audience response systems for in-class quizzing, mini case studies, role plays, and simulations. Results of on-course assessment items, consisting of on-line quizzes, was compared in order to determine whether active learning approaches improved academic performance. We found that academic performance increased across the cohorts when first implemented as flipped classroom, and the increase was maintained in the subsequent years focussing on the active learning strategies alone. We conclude that the introduction of active learning experiences to this class enhanced engagement and academic performance across the student cohorts.
\end{abstract}

\section{Introduction}

The number of students studying university courses in Australia has been increasing since 2009, when government funded places were uncapped. Increasing numbers of students brings increasing student diversity. This diversity can be on many fronts, including academic ability, learning styles, first-in-family status and ethnicity; all of which impact on learning success (Broughan \& Hunt 2012). Increasing student numbers also leads to larger class sizes. Producing meaningful learning experiences for large, diverse groups of students is a challenge that requires changing teaching practice for most traditional academics. There is evidence for novel active learning experiences enhancing student success (Freeman et al. 2014; Preville 2018) and yet academics are slow to take up these practices. This is due in part to lack of awareness of the evidence regarding active learning, and the personal success of the academics in the absence of active learning experiences. In addition, many academics are challenged by the need to learn different approaches to teaching (Handelsman et al. 2004). Here, we report the introduction of novel learning experiences in the physiology component of a large, mixed cohort, first year anatomy and physiology subject for allied health students. In addition, we report the changes in results of on-course quiz items (short summative quizzes, consisting of multiple choice questions delivered during the semester, as opposed to invigilated exams delivered at the end of semester) to determine the effect of the teaching innovations on academic performance, over three consecutive years. 


\section{Why we needed to change}

Prior to 2015, we had been teaching anatomy and physiology to first year allied health students using traditional didactic delivery, comprising three fifty-minute lectures and one two-hour practical class per week. The allied health programmes include students studying Occupational Therapy (OT), Physiotherapy (Physio), and Sport and Exercise science (Sport) degrees; the lectures were delivered to a combined class of approximately 225 students and the practical classes separately to each discipline. The majority of students come to us directly from high school, with no scientific prerequisites required for enrolment in the subjects. The subject was characterised by high failure rates, which varied across the different student cohorts. The average failure rate over the period 2010-2014 was 22\% across all cohorts and varied from $4 \%$ in the Physio cohort, to $28 \%$ for the Sport cohort.

In 2015, we decided to make a concerted effort to address the high failure rate and began by characterising the student's academic and social diversity. Our class size was approximately 225 and the students were of very diverse background, which varied across degree programmes. This is presented in Table 1 where the student entry scores are presented as Overall Position (OP) rankings. An OP of 1 is equivalent to an Australia Tertiary Admission Rank (ATAR) of 99 or higher and is the highest ranking of academic achievement; and an OP of 22 is equivalent to ATAR of 30 and indicates low preparedness for tertiary study.

Table 1: Student Demographics for 2015

\begin{tabular}{|c|c|c|c|}
\hline Cohort & $\begin{array}{c}\text { Overall Position } \\
\text { (OP) range }\end{array}$ & \% OP > 15 & \% First In Family \\
\hline Occupational Therapy & $1-21$ & 30 & 63 \\
\hline Physiotherapy & $1-12$ & 0 & 38 \\
\hline $\begin{array}{c}\text { Sport and Exercise } \\
\text { Science }\end{array}$ & $1-22$ & 54 & 60 \\
\hline
\end{tabular}

Given this broad diversity of student background, our initial intent was to increase student activity and engagement in the learning process by redesigning the subject to accommodate a 'flipped classroom' delivery model. We decided to introduce students to this novel way of learning by partially flipping the first semester subject - the physiology component was presented as flipped classroom. Reflection on the first iteration of this redesign revealed that the students were not engaging with the materials before class as intended, but were fully engaged by the in-class learning activities. On this basis our focus was on optimising the learning activities in subsequent years. We report on the partial redesign process here. In the second semester subject, all material was presented as flipped classroom, and we report on the fully flipped subject in a subsequent paper (Zimanyi, Emtage \& Megaw 2019).

\section{The flipped classroom and active learning}

Abeysekera and Dawson (2015), in a theoretical pedagogical discourse, define the flipped classroom as a:
"set of three pedagogical approaches which:
1. move most information-transmission teaching out of the class
2. use class time for learning activities that are active and social
3. require students to complete pre-and/or post-class activities to fully benefit from in-class work." $(1, p .3)$ 
Attempts have been made to measure whether the flipped classroom is an effective learning environment by determining student perception, and by examining changes in academic performance. The findings of studies of student perception of the flipped classroom are unclear, with students finding the flipped approach useful (Karanicolas, Snelling \& Winning 2018), preferring flipped classroom over the traditional classroom (McLaughlin et al 2014; Gopalan 2019), being equally satisfied with both (Zieglemeier \& Topaz 2015), or liking the pre-class activities but wanting to do them during class time (Kurtz, Tsimerman \& Steiner-Lavi 2014). Jensen and colleagues (2015) report that students in both traditional and flipped classrooms consider the time spent with the instructor as most influential, independent of the content delivery style (Jensen, Kummer \& Godoy 2015).

A number of studies also examine the changes in academic performance where the flipped classroom has been adopted. Good (2016) utilized the flipped classroom in a biology subject and found lower academic performance by students, other studies have found no change in academic performance (Jensen et al. 2015; Zieglemeier \& Topaz 2015), and others have reported increases in student performance with flipped classroom delivery (McLaughlin et al. 2014; Gopalan 2019). McLaughlin and colleagues (2014) studied a pharmaceutics subject of 162 students, including cross campus delivery and students attending via video conference. They report a modest (3\%) increase in exam performance with flipped classroom delivery. Interestingly, a study by Setern et. al. (2019) found that flipped classroom delivery did not increase the academic performance of low socio-economic and minority students.

Flipped classroom delivery generally relies on active learning strategies being deployed in the face-to-face component. A number of studies have reported on the efficacy of introducing active learning processes. The most convincing evidence for increased performance can be found in a study by Freeman and colleagues (2014). Their report comprises a meta-analysis of 225 studies of passive versus active teaching strategies and finds a $6 \%$ increase in exam performance with active learning strategies.

\section{What we did in the classroom}

Prior to 2015, the subjects were presented using traditional didactic methods - three 50 minute lectures per week, with one 2 hour practical per week. Students encountered material for the first time during the 'stand and deliver' lectures which were recorded and made available on the learning management system (LMS) for later viewing; limited opportunities for questions were provided. The practical classes for the physiology component were a combination of workbook exercises with some limited 'true' wet-lab practical activities. In general students engaged with the practical exercises on an individual basis with limited instructor supervision and input. The subjects were assessed on-course with 4 quizzes covering 3-4 weeks of material each, and by end of semester theory and practical examinations.

On the basis of findings that flipped classrooms appeal more effectively to a wide array of learning styles than traditional classrooms (Lage, Platt \& Treglia 2000), we introduced flipped classroom delivery to the four weeks of physiology covered in the thirteen-week long first semester, first year anatomy and physiology subject in 2015. We chose this 'partial' flip of delivery as a mechanism to prepare students for 'fully' flipped delivery in the second semester first year anatomy and physiology subject, where both the anatomy and physiology component were redesigned, initially using a flipped classroom approach. In addition to changing the delivery, the subject assessment was modified to include weekly quizzes, and a group based project. 
The four weeks of the physiology 'partial flip' were non-consecutive, with students attending one (50 minute) interactive session and one 2 hour workshop each week. The remaining nine weeks of anatomy were delivered by traditional didactic methods described above. We designed the flipped classroom using the 5E's design paradigm (Bybee et al. 2006). In this paradigm, activities were designed to meet each of Engage, Explore, Explain, Elaborate, and Evaluate strategies. Effectively, students were provided, via the LMS, with learning objectives, textbook readings, videos (some YouTube, some custom made), and focus questions for each week. In order to shift the information transmission to an out of class activity, the intent was that students would engage with this material prior to the interactive session.

The interactive session was a series of mini-lectures covering key concepts. Each mini-lecture lasted between 5-10 minutes and began with 2-3 individual audience response system questions designed to indicate the level of understanding of a topic the students had. Students were free to ask questions and request further clarification of information. These sessions were recorded and the lecture slides posted to the LMS after the interactive session was complete. The audience response system used was Turning Technologies ${ }^{\circledR}$ Turning Point ${ }^{\circledR}$ software integrated with Microsoft Power Point ${ }^{\circledR}$. Students were provided with QT keepad devices to respond. This software allows multiple format questions to be integrated directly into a power point presentation. The QT keepads include a full QWERTY keyboard, hence allowing for short answer style questions. The most common question type we used was the multiple choice question and occasional short answer questions requiring a single word response or a numerical response question was used. Students respond to the questions as presented and discussion of responses follows. The advantage of using an audience response system is that it allows students to respond anonymously to questions in real time and it allows the instructor to correct misconceptions immediately.

During the 2 hour workshop, activities were based on key concepts, and designed to engage different learning styles (for a summary of weekly design see Table 2). The activities included case studies, role plays, and simulations. Group and team based learning have been shown to be effective strategies for improving academic performance in large allied health classes (Rathner $\&$ Byrne 2014). Group based activities also add a social component to the learning process. We developed case studies and role plays specifically as group-based activities. Three to four very brief case study topics were presented each week and the students allotted time in the workshop sessions to explore the topics in groups of 3-5. Minimal direction was provided to students regarding the approach to these case studies in the belief that once engaged with the topics the students would produce questions and seek clarification as required.

The role plays were described in the workshop workbook and students provided with materials intended to act as 'props' for the students to perform the role play based on their understanding of key concepts. The concepts described for role-play included 'membrane transport', the 'sliding filament' theory of muscle contraction, and action potentials. The 'props' included such things as orange safety mesh to represent a membrane, various coloured party hats to designate different ions or sarcomeric components. Again, students were allocated time in the workshop to work through the role plays in groups of 3-5, with minimal direction.

The simulations were either presented to small groups of students by an instructor utilising various teaching 'props' as appropriate for the concept being simulated or carried out directly by students using props. For example, simulation of an action potential was achieved using a whiteboard, and various coloured and shaped magnets to represent ions and ion channels; 
simulation of glomerular filtration was achieved utilising garden hoses, irrigation filter cartridges with holes, and various buckets - performed outside, for obvious reasons (Figure 1A \& B); and simulation of airways restriction by inflating balloons through straws (Figure 1C). Performing these simulations required input from students, based on their understanding of the concepts.
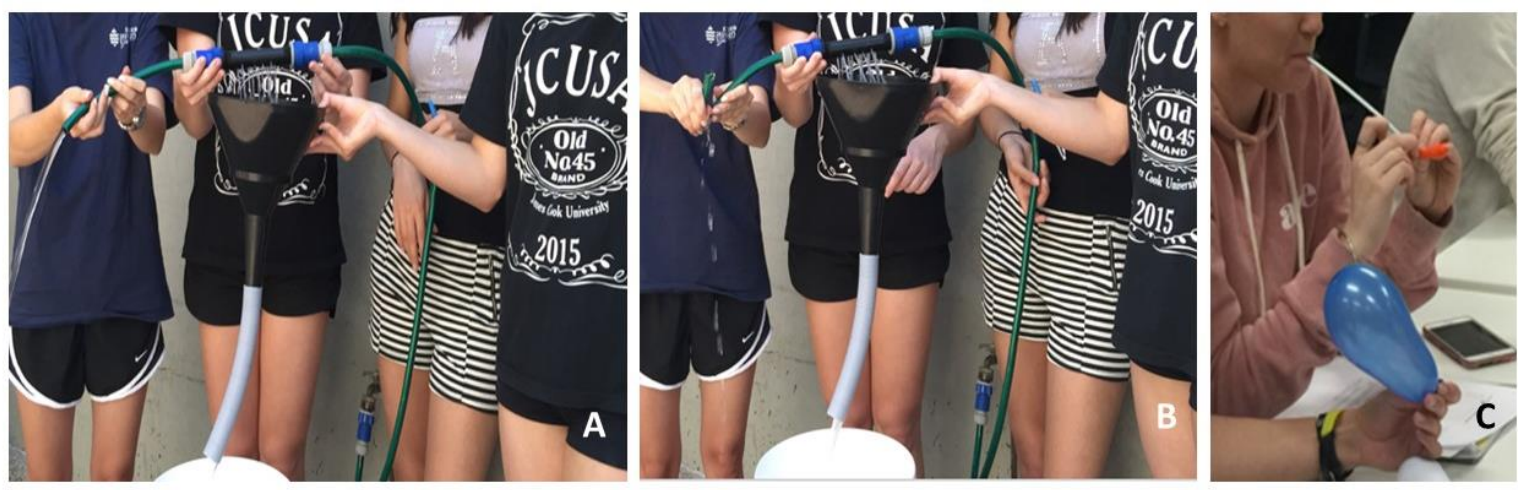

Figure 1: Simulations

A\&B: A model of the glomerulus was constructed using garden hoses, irrigation filters and buckets (A). Students explore the effects of altering the diameter of the efferent arteriole on glomerular filtration rate $(B$, far left).

\section{C: Students simulated airways restriction by inflating balloons, first without a drinking} straw and then through a drinking straw.

In 2016, we made alterations to the redesign (Table 2) in response to the 2015 observations and student feedback. Using the analytics function of our LMS we were able to ascertain that students were not engaging with the materials before class as intended for the flipped component. It was obvious, however that the students were fully engaged in the in-class learning activities. On this basis, we shifted our focus to further refinement of the learning activities and removed the requirement for students to engage with the materials before class. The refinements increased face-to-face time with the students, which has been found to enhance student perception of increased learning support (Page et al. 2006)

Students commented that the videos sourced externally were not as helpful as those that were custom-made. To address this, we custom-made videos for each learning objective. These videos, lasting no longer than 6 minutes, clarified the key points and depth of material the students needed to know for each learning objective. These were made using Techsmith Camtasia (Version 8) recording and editing software, and were posted to the LMS the week prior to delivery. We also introduced an electronic textbook with integrated online learning platform, which included videos and other electronic learning support activities.

In addition, students commented that the use of the audience response system in the interactive sessions took up too much time in the logistics of distributing keepads and dealing with technical issues; and instructors observed that the timing of the audience response questions in the interactive sessions was ineffective. In response, we modified the interactive sessions so that the audience response system questions came at the end of the mini-lecture (instead of at the beginning) and were completed as group work instead of individual responses. This reduced the time taken up by the logistics of distributing the keepads; it also reduced the number of technical problems as it reduced the number of keepads in use. We also added paper-based activities such as 'fill-in-the-blank' statements, cross words, and 'word-bingo' games to increase the variety of activities. Word-mint Puzzle Maker (https://wordmint.com/) software was utilised to facilitate the preparation of these paper-based activities. 
Table 2: Details of subject redesign for 2015, 2016, and 2017

\begin{tabular}{|c|c|c|c|}
\hline Year & 2015 & 2016 & 2017 \\
\hline $\begin{array}{l}\text { Materials provided on } \\
\text { LMS before class }\end{array}$ & $\begin{array}{l}\text { Students instructed to } \\
\text { complete these before } \\
\text { class } \\
\text { Learning objectives } \\
\text { Textbook readings } \\
\text { YouTube and custom } \\
\text { videos } \\
\text { Focus questions }\end{array}$ & $\begin{array}{l}\text { No requirement for students to } \\
\text { engage with these before class } \\
\text { Learning objectives } \\
\text { Custom videos explaining each } \\
\text { learning objective } \\
\text { e-Textbook readings } \\
\text { Focus questions }\end{array}$ & $\begin{array}{l}\text { As per } \\
2016\end{array}$ \\
\hline Interactive session & $\begin{array}{l}\text { Concept mini-lectures } \\
\text { Individual audience } \\
\text { response Questions at } \\
\text { beginning of each } \\
\text { mini-lecture }\end{array}$ & $\begin{array}{l}\text { Concept mini-lectures } \\
\text { Group audience response } \\
\text { questions } \\
\text { Questions at end of each mini- } \\
\text { lecture }\end{array}$ & $\begin{array}{l}\text { As per } \\
2016\end{array}$ \\
\hline Workshop activities & $\begin{array}{l}\text { Simulations and role- } \\
\text { plays with some } \\
\text { instruction } \\
\text { Case studies with } \\
\text { minimal instruction } \\
\text { Summative quiz. }\end{array}$ & $\begin{array}{l}\text { Simulations and role-plays with } \\
\text { structured guidance. } \\
\text { Case studies performed in } \\
\text { groups with posters produced. } \\
\text { Posters presented to peers with } \\
\text { instructor guidance. } \\
\text { Summative quiz. }\end{array}$ & $\begin{array}{l}\text { As per } \\
2016\end{array}$ \\
\hline
\end{tabular}

Students felt the activities in the workshops were disorganised. The instructors also observed that the learning activities in the workshops required more support and structure, which agreed with the student feedback mentioned above. According to Karanicolas and colleagues (2018), students appreciate sessions that are well organised, and have a clear sequence in class activities and content. Based on this we modified the workshop sessions in that further instruction and scaffolding was provided for the implementation of the case studies, role plays and simulations. The case studies where more rigorously organised, with each group of students preparing a poster for one case study and presenting the posters to their peers (Figure 2) with questioning and clarification from the instructor. These posters were then photographed and posted to the LMS for students' reference.

The role-plays were performed as whole-of-class activities, under the guidance of an instructor (Figure 3). Students input to how the role-play should proceed was sought and incorporated into the activity if appropriate. The instructor ensured that all students were allocated a role and engaged in this activity.

In 2017 , no further changes were made to the redesign. 

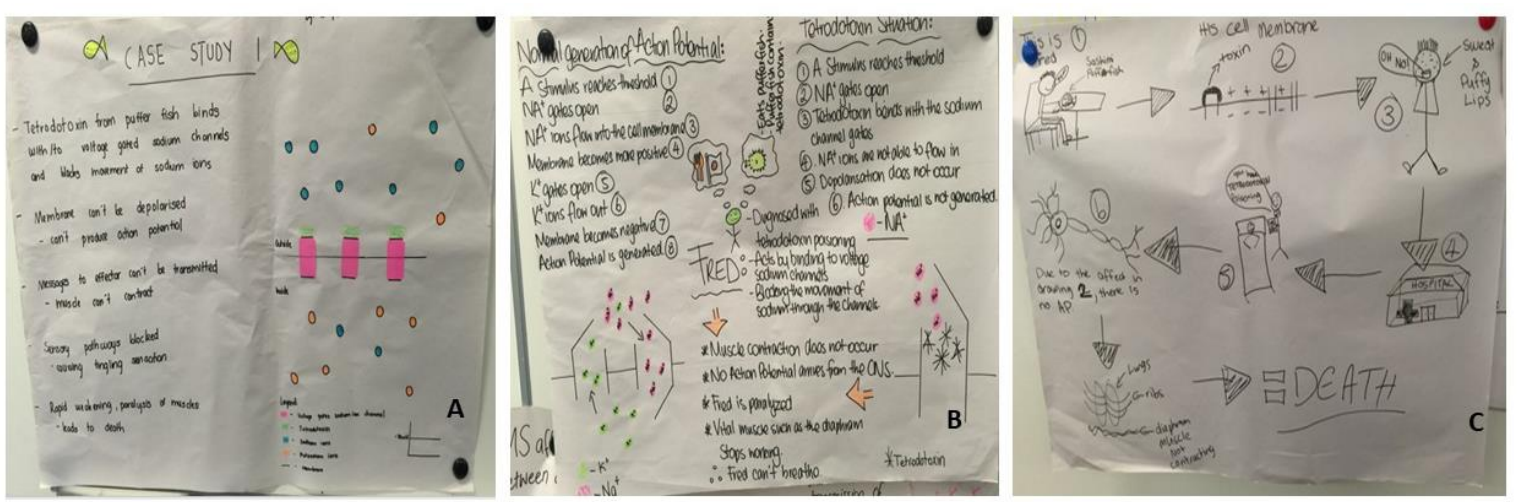

Figure 2: Case study posters

Groups of students produced posters addressing short case studies. More than one group worked on each topic and the posters produced were quite diverse, even though the topic was the same. A, B and $C$ illustrate the range of posters for the same topic.

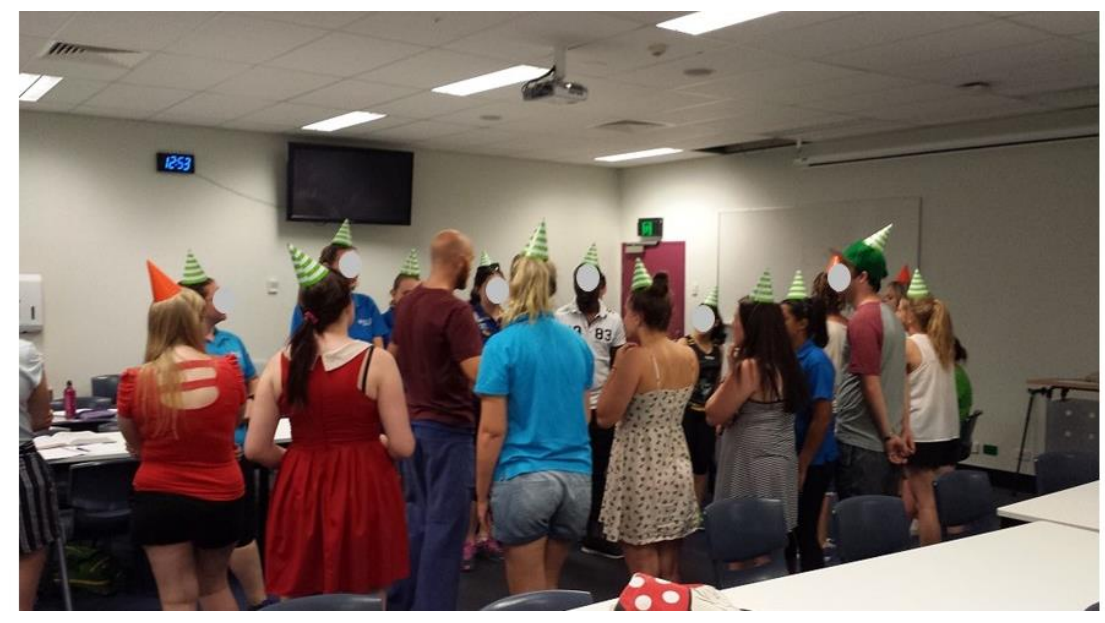

Figure 3: Role-plays

Role plays were performed as whole class exercises using various materials as props, including party hats, to help identify roles. Here a group interacts with the instructor in preparation for role playing sarcomeric contraction.

\section{Did Students' academic performance improve?}

We analysed academic performance by looking at the results of on-course quizzes for physiology material only. In 2014, these quizzes were presented as paper based quizzes covering 5 weeks of material. In the subject redesign, these quizzes were presented at the conclusion of each workshop. These quizzes were delivered online and together contributed $30 \%$ of the overall subject mark.

Analysis of mean quiz scores across cohorts by one-way ANOVA revealed a statistically significant difference at the $\mathrm{p}<0.05$ level for all twelve groups: $F(11,919)=47.494, \mathrm{p}=0.001$. Post-hoc comparison using Tukey Honestly Significant Difference (HSD) revealed varying score gains across cohorts. In accordance with previous findings (Freeman et al. 2014; Kurtz et al. 2014), academic performance increased across all cohorts with the subject redesign in 2015 . This increase was of 19 percentage points, on average. In 2016, increased performance was again 
seen, compared to the 2014 performance across all cohorts, however, gains were not as great when compared to the 2015 performance. In 2016 the mean on-course quiz grades were on average, 6 percentage points less than in 2015 (Table 3). This is likely due to normal inter-year variability. In general, some years are more academically able than others. In 2017 there was no significant differences in the mean on-course quiz grades, compared to the 2016 grades. The decline in the grades for 2016-2017 when compared with the grades for 2015 may also be due to the change in focus from a flipped classroom to active learning. Maybe the students in 2015 were better prepared for the face-to-face sessions by the requirement to engage outside of the classroom, which lead to greater gains in grades. What is clear is that the redesigned subject produced academic performance gains over the more traditional delivery used in 2014.

Table 3: Mean on-course quiz results as percentage scores for each cohort and year of the study. *significant increase compared to 2014 score $(p<0.05)$, $\uparrow$ significant decrease compared to 2015 score $(\mathbf{p}<0.05)$

\begin{tabular}{|l|l|l|l|l|}
\hline Year & $\mathbf{2 0 1 4}$ & $\mathbf{2 0 1 5}$ & $\mathbf{2 0 1 6}$ & $\mathbf{2 0 1 7}$ \\
\hline OT & $59.18 \pm 1.43$ & $80.32 \pm 1.36^{*}$ & $72.70 \pm 1.35^{* \dagger}$ & $72.90 \pm 1.40^{* \dagger}$ \\
\hline Physio & $73.46 \pm 1.64$ & $90.74 \pm 0.66^{*}$ & $82.86 \pm 1.00^{* \dagger}$ & $81.39 \pm 1.27^{* \dagger}$ \\
\hline Sport & $58.17 \pm 1.26$ & $76.42 \pm 1.10^{*}$ & $73.99 \pm 1.69^{*}$ & $67.46 \pm 1.86^{*}$ \\
\hline
\end{tabular}

We measured academic performance by comparing scores of on-courses quizzes. The majority of questions for specific topic areas on the quizzes were the same each year. The 2014 quizzes, when the materials were delivered didactically, were delivered as part of 2 large combined anatomy and physiology quizzes after 5 weeks of instruction. The 2015, 2016, and 2017 quizzes were delivered at the end of one weeks' instruction of the topic and included some learning activity specific questions. Compared to the quizzes in 2014, the quizzes in 2015, 2016, and 2017 covered less material, were shorter in duration, and covered material which was fresh in the students' minds. This variability in quiz delivery may have contributed to increased academic performance.

One of our biggest challenges was to redesign the subject to enhance performance of the less academically prepared students without adversely affecting the performance of the more academically able students. Both the better academically prepared cohort (Physio) and least prepared cohort (Sport) showed academic gains, suggesting we successfully met this challenge. Indeed, the academic gain of the Sport cohort was greater than for the Physio cohort, which further suggests success in this challenge. As the Physio academic performance was already good, there was less gain to be had than for the Sport cohort, in any case.

It appears that the increase in academic performance was due to the increase in 'active' learning of the students as opposed to the introduction of flipped classroom, per se, as contended by Jensen and colleagues (2015). This is evidenced by the maintained increase in academic performance after the 'flipped' component was removed in the refinement phase. Student feedback indicated an increase in student satisfaction after the refinement of the activities in 2016, which also supports this notion. In the refinement, more explicit instruction was provided regarding the use of the resources and this enabled students to better utilize those resources in their learning activities. There is ample evidence for active learning strategies alone producing greater student satisfaction and academic performance (Cavanagh 2011; Preville 2019). In addition, this instruction meant increased interaction between students and instructors, which has also been shown to enhance the learning process (Jensen et al. 2015). 
In our experience, students fully engage with active learning strategies and their academic performance is enhanced as a result. Continued reflection and enhancement of this teaching approach will maintain the gains in academic performance. In the next step of the process, we need to determine whether exposure to these learning techniques over the course of a full subject has similar effects on student performance.

\section{Acknowledgements}

We would like to acknowledge Dr Kathryn Meldrum (James Cook University, Cairns) for her assistance with the 5Es design of the flipped classroom, and Dr Ranjna Kapoor and Dr Lisa Chilton for their assistance with manuscript preparation.

This study was conducted under approval from James Cook University Human Ethics committee number H6099.

\section{References}

Abeysekera, L., \& Dawson, P. (2015). Motivation and cognitive load in the flipped classroom: definition, rationale and a call for research. Higher Education Research and Development 34(1),1-14.

Broughan, C., and Hunt, L. (2012). Inclusive teaching. In L.Hunt \& D. Chalmers (Eds.), University teaching in focus: A learning-centred approach (pp. 182-198.Camberwell: ACER press

Bybee, R. W., Taylor, J. A., Gardner, A., Van Scotter, P., Carlson Powell, J., Westbrook, A., \& Landes, A. (2006). The BSCS 5E Instructional Model: Origins, Effectiveness and Applications. Retreived November 2016 from https://www.bscs.org/sites/default/files/_legacy/BSCS 5E_Instructional_ModelExecutive Summary 0. pdf

Cavanagh, M. (2011). Students' experiences of active engagement through cooperative learning activities in lectures. Active Learning in Higher Education 12(1), 23-33.

Freeman, S., Eddy, S. L., McDonough, M., Smith, M. K., Okoroafor, N., Jordt, H. \& Wenderoth, M. P. (2014). Active learning increases student performance in science, engineering, and mathematics. Proceedings of the National Academy of Science 111(23), 8410-8415.

Good, L. (2016). Implementation of flipped classrooms in a non-major biology course. Retrieved November 2016 from http://digitalcommons.murraystate.edu/cgi/viewcontent.cgi?article=1105\&context=scholarsweek

Gopalan, C. (2019). Effect of flipped teaching on student performance and perceptions in an Introductory Physiology course. Advances in Physiology Education 4, 28-33;

Handelsman, J., Ebert-May, D., Beichner, R., Bruns, P., Chang, A., DeHaan, R., Gentile, J., Lauffer, S., Stewart, J., Tilghman, S. M., Wood, W. B. (2004). Scientific Teaching. Science 304,521-522.

Jensen, J. L., Kummer, T. A., \& Godoy, P. D. d M. (2015). Improvements from a flipped classroom may simply be the fruits of active learning. CBE-Life Sciences Education 14:ar5, 1-12.

Karanicolas, S., Snelling, C., \& Winning, R. (2018). Translating concept into practice: enabling first-year health sciences teachers to blueprint effective flipped learning approaches. Retrieved January 2019 from www.adelaide.edu.au/teaching-projects/flipped-classroom/

Kurtz, G., Tsimerman, A., \& Steiner-Lavi, O. (2014). The flipped classroom approach: the answer to future learning? European Journal of Open, Distance and e-Learning 17(2), 171-181.

Lage , M. J., Platt, G. J., \& Treglia, M. (2000) Inverting the classroom: A gateway to creating an inclusive learning environment. Journal of Economic Education, 31, 30-43.

McLaughlin, J. E., Roth, M. T., Glatt, D. M., Gharkholonarehe, N., Davidson, C., Griffin, L. M., Esserman, D. A., \& Mumper, R. J. (2014). The flipped classroom: A course redesign to foster learning and engagement in a health professions school. Academic Medicine 89(2), 236-243.

Page, J., Meehan-Andrews, T., Weerakkody, N., Hughes, D.L., \& Rathner, J.A. (2017) Student perceptions and learning outcomes of blended learning in a massive first-year core physiology for allied health subjects Advances in Physiology Education 41: 44-55

Preville, P. (2018). The Active Learning Handbook. tophat.com

Rathner, J. A., \& Byrne, G. (2014) The use of team-based, guided inquiry learning to overcome educational disadvantages in learning human physiology: a structural equation model Advances in Physiology Education 38: 221-228.

Steren, E., Greenberg, K., Moore, O., \& Yankovich, M. (2019) Effects of the flipped classroom: Evidence from a randomized trial. School Effectiveness and Inequality Initiative Discussion paper \#2019.07. Retrieved September 2019 from http://seii.mit.edu/research/study/effects-of-the-flipped-classroom-evidence-from-arandomized-trial/ 
Ziegelmeier, L. B., \& Topaz, C. M. (2015). Flipped Calculus: A study of student performance and perceptions. Problems, Resources, and Issues in Mathematics Undergraduate Studies 25(9-10), 847-860.

Zimanyi, M. A., Emtage, N. F., \& Megaw, P. L. (2019). Redesigning first year anatomy and physiology subjects for Allied Health students: Impact of active learning strategies. International Journal of Innovation in Science and Mathematics Education, 27(8), 36-48. 